NOTICE: this is the author's version of a work that was accepted for publication in Personality and Individual Differences. Changes resulting from the publishing process, such as peer review, editing, corrections, structural formatting, and other quality control mechanisms may not be reflected in this document. Changes may have been made to this work since it was submitted for publication. A definitive version was subsequently published as: Wouters, S., Verschueren, K., Briers, V., \& Janssen, R. (2016). Development and validation of a Self-esteem Contingency Questionnaire for Adolescents. Personality and Individual differences, 99, 295-301.

\title{
Development and Validation of a Self-Esteem Contingency Questionnaire for
}

\section{Adolescents}

$$
\text { Wouters }^{1} \text {, Verschueren }{ }^{1} \text {, Briers }{ }^{1} \text {, and Janssen }{ }^{2}
$$

\footnotetext{
${ }^{1}$ School Psychology and Child and Adolescent Development, Faculty of Psychology and Educational Sciences, KU Leuven, Belgium

${ }^{2}$ Educational Effectiveness and Evaluation, Faculty of Psychology and Educational Sciences, KU Leuven, Belgium
}

Sofie Wouters is a postdoctoral fellow of the Research Foundation - Flanders (FWO). The authors would like to thank Lette van Bael for her assistance in this research as part of her master's thesis in psychology.

N.B.: When citing this work, cite the original article (see above). 


\begin{abstract}
Self-esteem (SE) contingency refers to the extent to which one's level of self-esteem depends on meeting certain internal or external criteria and has been identified as a psychological risk factor. Addressing limitations of existing SE contingency questionnaires, we developed a domain-specific situation-response questionnaire for adolescents that (1) measures SE contingency in domains which are considered important for adolescents, based on multidimensional self-concept models, and (2) includes balanced numbers of positive and negative items per domain, allowing to distinguish between upward and downward contingencies. The current findings support the reliability and validity of the new 24 -item questionnaire in a sample of high school students $(\mathrm{N}=599$, age range 15-22). Confirmatory factor analyses supported the 4 (domains) x 2 (valence) structure of our questionnaire and its convergent and discriminant validity was established. Finally, external validity was supported by finding the expected associations with psychological control and depressive symptoms.
\end{abstract} Key-words: self-esteem contingency, self-esteem level, adolescence, questionnaire. 
Development and Validation of a Self-esteem Contingency Questionnaire for Adolescents

\section{Introduction}

Self-esteem (SE) is considered a heterogeneous construct consisting of multiple aspects beyond its level (Heppner \& Kernis, 2011). One such other aspect is SE contingency which refers to the degree to which one's SE depends on attaining external or internal standards. Adolescents higher on SE contingency feel they have to meet certain criteria to be able to perceive themselves as good and worthy. Research and theorizing (e.g., Deci \& Ryan, 1995; Wouters, Doumen et al., 2013) suggest that this need to incessantly prove oneself may, at least to some extent, be explained by the level of psychological control exerted by the parents. Individuals lower on SE contingency, on the other hand, have SE that is less dependent on being successful or is less threatened by failure. Several studies have already demonstrated that higher levels of SE contingency are positively associated with several negative outcomes, sometimes even above and beyond any effect of SE level (e.g., Bos et al., 2010; Burwell \& Shirk, 2006; Wouters, Duriez et al., 2013).

Although several instruments have been developed to measure SE contingency, they all share one or more limitations we aim to address by developing a new instrument for measuring adolescents' SE contingency.

\subsection{Measuring Self-esteem Contingency}

In the current study, we focus explicitly on developing a new domain-specific SE contingency questionnaire for adolescents, thereby accounting for the possibility that adolescents' level of SE contingency differs across various domains. Additionally, these domains may each have their own correlates and consequences. The Contingencies of SelfWorth Scale (CSWS; Crocker, Luhtanen, Cooper, \& Bouvrette, 2003) is an example of a domain-specific questionnaire in which multiple factors are expected to emerge (see Table 1 for an overview of existing domain-specific questionnaires). Although there are also 
questionnaires which measure SE contingency as a general tendency (e.g., the Contingent Self-Esteem Scale; Paradise \& Kernis, 1999) and they may supplement domain-specific questionnaires, we will not consider them in the current study.

A first limitation of domain-specific SE contingency questionnaires is that there seems little consistency in the specificity (e.g., appearance vs. body weight) and the number of domains (one domain vs. seven domains), which may be at least partly due to the lack of a clear theoretical rationale. Also, some of these measures may not be ideally suited for use in adolescent samples as they were originally developed for older students or adults.

A second limitation concerns the valence of the items. As individuals high on selfesteem contingency are expected to experience both self-esteem boosts and sharp self-esteem drops depending on whether they reach their self-related standards or not, items may be upward or downward (e.g., 'My self-esteem strengthens considerably when others seek my company', upward item Relation Based Self-Esteem Scale; 'I feel bad about myself whenever my academic performance is lacking', downward CSWS-item). Additionally, items may be valence-free or neutral, not referring to positive or negative events (e.g., 'If other people's feelings about me change, my feelings of self-worth change as well', Self-Worth Contingency Questionnaire). Some SE contingency questionnaires only contain neutral items, whereas others comprise an unbalanced mix of upward and downward items and some have both. As an exception, Vonk and Smit (2012) developed a SE contingency questionnaire using balanced numbers of upward and downward items in three extrinsic contingency domains (i.e., performance, social approval, and appearance). Results supported the distinction between upward and downward contingencies in these three extrinsic domains. Moreover, their findings suggested that having downward contingencies may be more detrimental for one's well-being than having upward contingencies. Nevertheless, this questionnaire was not specifically designed for adolescents and validated in an older sample $\left(M_{\mathrm{age}}=38.6\right)$. 


\subsection{Research Aims}

To address the two main limitations of existing measures, we developed a new brief domain-specific SE contingency questionnaire for adolescents tapping different self-concept domains deemed important for adolescents. We specifically targeted adolescents because their SE may be particularly vulnerable and contingent (Burwell \& Shirk, 2006; Harter, 2006). Responding to the need for a more clear theoretical rationale for identifying important contingency domains for adolescents, we used information from multidimensional selfconcept models (Harter, 1999; Marsh \& Shavelson, 1985; Shavelson, Hubner, \& Stanton, 1976) and two well-established and validated measures of adolescent self-concept, the SelfPerception Profile for Adolescents (SPPA; Harter, 1988) and the Self-Description Questionnaire-II (SDQ-II; Marsh, 1992) (see Table 2). Despite an obvious link between SE level and SE contingency, surprisingly few connections have been made at the measurement level. Therefore, we chose to include items referring to specific and tangible events in six selfrelevant domains (i.e., academic competence, physical appearance, physical competence, social acceptance, close friendships, and romantic attractiveness) based on a comparison of the SPPA and SDQ-II items. Additionally, we used a balanced number of negative and positive items per contingency domain, allowing us to examine differential correlates of downward versus upward contingencies.

In addition to developing this questionnaire, we aimed to investigate its reliability and validity. In line with the findings of Vonk and Smit (2012), we expected to find support for a $6 \times 2$ factor structure capturing the aforementioned six domains and two valences (i.e., upward/positive and downward/negative items). Additionally, as an indication of convergent validity, we expected strong correlations between corresponding domains of the new questionnaire and the CSWS (i.e., Social acceptance/Others' approval, Academic competence, and Physical appearance/Appearance). As an indication of discriminant validity 
and based on previous research, we expected small to moderate (negative) correlations between corresponding SE contingency and SE level subscales (e.g., Bos et al., 2010; Wouters, Doumen et al., 2013; Wouters, Duriez et al., 2013). Finally, as support for external validity and based on previous research (e.g., Burwell \& Shirk, 2006; Wouters, Doumen et al., 2013) and theorizing (e.g., Deci \& Ryan, 1995), we expected positive associations between perceived parental psychological control and SE contingency and between SE contingency and self-reported depressive symptoms. Based on the results of Vonk and Smit (2012), we further hypothesized that relations between SE contingency and depressive symptoms would be stronger for downward contingencies than for upward contingencies.

\section{Method}

\subsection{Participants}

In total, 599 high-school students participated (49\% male; mean age $=17.7$ years, $S D$ $=1.1$ year), who were recruited by 292 undergraduate psychology students from a large university in Flanders, the Dutch-speaking part of Belgium. Each student was given a profile of two high-school students he or she had to contact specifying the gender and the educational track of the student to guarantee a good cross-section of the population. In the Flemish educational system, four main tracks are distinguished: an academic, technical, artistic, and vocational track. The student was free to choose a high-school student from Grades 10 till 13. Most students (96\%) in our sample spoke Dutch at home, $63 \%$ of the participants had at least one parent with a college or university degree, and $24 \%$ had parents with only a degree of high school or elementary school (13\% of the parental educational level data were missing for one or both parents).

\subsection{Main questionnaires}

Students were informed to act as research assistants providing instructions to the respondents who filled out all questionnaires online. 
2.1.1. Self-esteem (SE) Contingency. To measure SE contingency, we used two instruments: our newly developed Self-esteem Contingency Questionnaire for Adolescents (SCQA) and the Contingencies of Self-Worth Scale (CSWS). The SCQA was constructed as a situation-response (SR) questionnaire, in order to maximize the content validity of the scale. The situations refer to three positive (e.g., when I'm invited to a party...) and three negative (e.g., when my hair looks bad ...) events in six different domains deemed important for adolescents, based on multidimensional self-concept models and questionnaires (see Table 2). Three domains were present in both Harter's SPPA and Marsh' SDQ-II (i.e., academic competence, physical competence, and physical appearance). For the social domain, however, the SDQ-II only mentions two broad Relationship subscales (opposite-sex and same-sex), whereas the SPPA mentions three specific subscales (i.e., Social acceptance, Close friendships and Romantic attractiveness). We decided to create separate subscales for the social domain, in line with the SPPA, allowing us to examine whether adolescents actually differentiate between SE contingency in these domains or not. In line with SE definitions, items directly referred to changes in SE or described changes in adolescents' thoughts and feelings about the self. A 6-point rating scale ranging from 1 (does not apply to me at all) to 6 (completely applies to me) was used.

The CSWS of Crocker and colleagues (2003) contains seven scales measuring SE contingency in seven different domains (see Table 1). In contrast to the SCQA, the CSWS was developed in samples of older (undergraduate) students, does not have balanced numbers of positive and negative items and does not refer to specific situations. Respondents answered items using a 7-point rating scale going from 1 (strongly disagree) over 4 (neutral) to 7 (strongly agree). We translated the CSWS into Dutch and had it back-translated into English by a professional translator. Cronbach's alphas of the subscales ranged from .73 to .95 . 
2.1.2. Level of self-esteem. To measure SE level, three subscales were selected from the short version of the SDQ-II (Marsh, Ellis, Parada, Richards \& Heubeck, 2005; translated by Simons and Vangenechten, 2002): academic competence, physical abilities, and physical appearance (each 4 items). One scale (romantic appeal; 5 items) was taken from the SelfPerception Profile for Adolescents (SPPA; Harter, 1988) and translated into Dutch for the present study and two final scales (close friendship and social acceptance; 5 items each) were taken from the Dutch version of the SPPA (CBSA; Treffers, Goedhart, Veerman, Van den Bergh, \& de Rycke, 2002). For all items, the response format of the SDQ-II (Marsh et al., 2005) was used. The respondents rated items using a 6-point scale ranging from 1 (false) to 6 (true). After deleting one item from the subscale Close Friendships (e.g., 'I don't have a close friend with whom I can share a secret'), all subscales were internally consistent ( $\alpha \geq .64)$.

2.1.3. Depressive symptoms. The 12 -item version of the Center for Epidemiologic Studies Depression scale (CES-D) of Roberts and Sobhan (1992; Dutch version by Hooge, Decaluwé, \& Goossens, 2000) was used to measure depressive symptoms. The respondents answered items on a 4-point scale ranging from 0 (seldom or never) to 3 (most of the time or always). Internal consistency was good $(\alpha=.81)$.

2.1.4. Psychological control. Perceived parental psychological control was measured using the Dependency-oriented and Achievement-oriented Psychological Control Scales (DAPCS; Soenens, Vansteenkiste, \& Luyten, 2010). This questionnaire distinguishes between two types of psychological control: Dependency-oriented psychological control refers to psychological control exerted by parents to make their children dependent on their emotional bond, whereas achievement-oriented psychological control refers to psychological control exerted by parents to make their child comply to their performance standards. Respondents answered items on a 5-point Likert scale ranging from 1 (completely false) to 5 (completely 
true). In the current study, both scales were internally consistent (alphas were .81 and .92 for dependency and achievement-oriented psychological control respectively).

\section{Results}

\subsection{Factorial Validity}

First, several alternative models were estimated and compared using Confirmatory Factor Analyses (CFAs) performed with Mplus Version 6.1 (Muthén \& Muthén, 1998-2010). The chi square was adjusted for possible non-normality by using MLR. Results, as shown in Table 3, clearly favored a model which accounted for the 6 (6 domains) x 2 (upward versus downward) structure of the SCQA.

The fit of the 12-factor model was good, but because some factors were strongly interrelated, this model was further adjusted. First, we noticed a correlation larger than 1 ( $r=$ 1.04) between the latent factors downward social acceptance and downward close friendship. Consequently, we decided to let the items of both factors load on one single factor and then we selected the three highest loading items to continue with. For reasons of symmetry, we did the same for upward social acceptance and upward close friendship $(r=.70)$ (see Table 4). We labeled both new factors as downward and upward 'peer relations' because both social acceptance and close friendships refer to peer relations. After making these adjustments, results suggested a linear dependency involving downward romantic attractiveness. As such, we decided to delete the items loading on this factor and its upward counterpart (for reasons of symmetry). This resulted in the final 8-factor model with four remaining domains, as shown in Table 4. The fit of this model was good and all standardized factor loadings were higher than .56 .

We cross-validated this final model in a second sample of 604 high-school students $(49 \%$ male; mean age $=17.6$ years, $S D=1.1$ year $)$, which was collected one year later using the same procedures as for our main sample. The fit of the final 8-factor model was also good 
in this second sample $\left(\right.$ scaled $\chi^{2}(224)=487.811, p<.001, \mathrm{RMSEA}=.044,90 \% \mathrm{CI}=[.039-$ $.049], \mathrm{CFI}=.927, \mathrm{SRMR}=.043)$ and all standardized loadings were higher than $.55 .{ }^{1}$

\subsection{Internal consistency and Descriptive Statistics}

Using the IBM Statistical Package for the Social Sciences (SPSS) Version 23 (IBM, 2015), we showed that the final eight SCQA subscales were internally consistent (see Table

4). Correlations between observed scale scores as well as means and standard deviations are reported in Table 5. All subscales were positively and significantly related to each other with correlations varying between .20 and .66 .

\subsection{Convergent and Divergent Validity}

Convergent validity of the SCQA was established by finding significant correlations from .36 to .66 between the corresponding subscales of the SCQA and the CSWS (Crocker et al., 2003; academic, appearance, and social domains). Discriminant validity was established because both self-esteem aspects (i.e., contingency and level) were only modestly correlated with each other within and across domains. Both negative and positive correlations were observed between SE level and SE contingency (see Table 5).

\subsection{External Validity}

As shown in Table 6, regressing SE contingencies on both forms of psychological control (controlling for sex and track) resulted in positive associations between psychological control and SE contingency. In general, dependency-oriented psychological control was associated with higher levels of SE contingency in the sports domain, whereas achievementoriented psychological control was mainly related to higher levels of SE contingency in the academic, appearance, and peer relations domains. Nevertheless, positive associations were also found between dependency-oriented psychological control and downward SE contingency in the academic and peer relations domains. Additionally, girls and students in 
more academically oriented tracks generally had higher levels of SE contingency than boys and students in less academically oriented tracks.

Furthermore, regressing depressive symptoms on upward and downward SE contingency (controlling for sex and track) showed that all downward contingencies were positively and uniquely related to depressive symptoms, beyond the negative effect of SE level (see Table 7). Results further indicated that upward contingencies were not significantly related to depressive symptoms, except for a negative association between upward sports contingencies and depressive symptoms. Additionally, girls and students in less academically oriented tracks experienced higher levels of depressive symptoms than boys and students in more academically oriented tracks.

Finally, we repeated all regression analyses with the corresponding subscales of the CSWS to compare with the SCQA results. Results (see Table 8) showed that the CSWS subscales had weaker relations with both psychological control and depressive symptoms as compared to the SCQA downward contingencies and acted differently from the upward contingencies towards depressive symptoms. Furthermore, when adding corresponding downward and upward contingencies to regressions, as mentioned in Table 8, downward contingencies were always significantly related to depressive symptoms $\left(\beta_{\text {academic }}=.32, p<\right.$ $\left..001 ; \beta_{\text {social }}=.10, p<.05 ; \beta_{\text {appearance }}=.22, p<.001\right)$, above and beyond any effects of the CSWS subscales. Relatedly, explained variance increased up to 1 to $7 \%$. These findings thus highlight the importance of developing a new SE contingency questionnaire.

\section{Discussion}

The present findings provide clear support for the reliability and validity of the SCQA, a new SE contingency questionnaire for adolescents overcoming limitations of existing questionnaires. Confirmatory factor analyses favored a $6 \times 2$ solution capturing the expected six contingency domains (i.e., academic competence, physical competence, physical 
appearance, social acceptance, close friendships, and romantic attractiveness) and two valences (i.e., upward/positive and downward/negative items), as would be expected from previous research (e.g., Vonk \& Smit, 2012). However, due to some overlap between the social and the close friendship domain and a linear dependency concerning romantic attractiveness, we decided to trim the twelve-factor model. This resulted in a well-fitting final model including the following eight dimensions of adolescent SE contingency that were found to be internally consistent: upward academic, downward academic, upward appearance, downward appearance, upward sports, downward sports, upward peer relations, downward peer relations. Additionally, this factor structure was cross-validated in another sample. Our findings thus confirm that adolescents also hinge their self-esteem upon successes or failures in domains identified as important in multidimensional self-concept models and related measures. Interestingly, adolescents do not seem to differentiate between their contingencies in the three social domains as identified within the SPPA.

Furthermore, convergent and discriminant validity were established by finding strong interrelations between corresponding subscales from the SCQA and the CSWS and only moderate associations between SE contingency and SE level in corresponding domains. This confirms that one's level and contingency of SE are two different aspects of SE, even in specific domains. Although we found several significant negative correlations between SE level and contingency, as expected (e.g., Bos et al., 2010; Wouters, Doumen et al., 2013; Wouters, Duriez et al., 2013), we also found significant positive correlations. These positive correlations most clearly emerged for upward contingencies. This is in line with findings from Vonk and Smit (2012) who reported a significant, positive correlation between upward performance contingencies and global SE level. Taken together, these findings suggest that making your SE dependent on positive events may actually be beneficial, for instance for one's SE level. However, it is unclear to date whether it is possible to have more upward 
contingencies without also raising one's level of downward contingencies. Hence, future research should focus on person-centered analyses to find out more about the co-occurrence of these two kinds of contingencies in adolescents.

Additionally, we found evidence supporting the external validity of the SCQA. Consistent with previous research (e.g., Wouters, Doumen et al., 2013) and theorizing (e.g., Deci \& Ryan, 1995), results yielded that parents who were perceived to control their children's thoughts and emotions made their children's self-esteem particularly contingent. Furthermore, students who let their self-esteem depend more on negative events in the contingency domains under consideration, also experienced more depressive symptoms than students who had less downward contingencies - even when controlling for domain-specific SE level. These results further strengthen the hypothesis that downward contingencies are particularly detrimental for adolescents' well-being (Vonk \& Smit, 2012) and they also qualify previous findings showing that (global) SE contingency did not have a unique (longitudinal) main effect on depressive symptoms beyond global SE level (Bos et al., 2010; Sowislo, Orth, \& Meier, 2014; Wouters, Duriez et al., 2013). Indeed, the use of a global measure of SE contingency and/or an unbalanced mix of upward and downward contingency items in previous studies may have obscured interesting differences.

Finally, there were some additional findings. First, we were able to show that the SCQA provides extra information beyond the CSWS (Crocket et al., 2003), which does not distinguish between downward and upward contingencies. For instance, whereas the downward contingencies generally had stronger positive relations with depressive symptoms than corresponding CSWS subscales, the upward contingencies were not (or negatively) related to depressive symptoms. Second, our results showed that girls' SE was more contingent than that of boys and they also reported more depressive symptoms than boys, which is in line with previous research (e.g., Crocker et al., 2003; Petersen et al., 1993; 
Wouters, Duriez et al., 2013). Additionally, we showed that students in more academically oriented tracks reported both higher levels of SE contingency and less depressive symptoms than students in less academically oriented tracks. Thus, other factors besides SE contingency seem needed to explain these differences in depressive symptoms between different tracks. Students in more academically oriented tracks may have higher levels of SE contingency because the demands and expectations for these students are often higher (Salmela-Aro \& Tynkkynen, 2012) and they may have internalized them. Nevertheless, these results need to be replicated before making any strong conclusions.

The present study has some limitations. First of all, we only used self-report questionnaires. Although we were mainly interested in adolescents' self-esteem and their own view on their world, it may have been interesting to add information from parents or peers. Second, we collected all data at one point in time which limits us in making conclusions regarding the direction of the observed effects. Even though we may hypothesize, for instance, that parents who are perceived to exert higher levels of psychological control make their children's SE more vulnerable, it is also possible that children with higher levels of SE contingency elicit higher levels of psychological control in their parents. Future studies should thus focus on examining our hypotheses longitudinally. Third, we did not consider explicitly whether our items refer to more internal or external standards of success or failure. It may be interesting to further examine this in future research. However, distinguishing between external and internal items may be complex. For instance, the item "I feel worthwhile when I perform well in a sports game" may be considered more internal as compared to, for example, an item referring more explicitly to praise by peers or teachers. On the other hand, it may also be regarded as external, because students will also look to external sources of information to know whether they (as an individual within their team) played well or not (i.e., effects of social comparison). Finally, we specifically examined a group of Flemish adolescents in the 
final years of high school. Hence, more research is needed in other countries and with younger adolescents, before generalizing our results to the entire population of adolescents.

Despite these limitations, the current findings show that we were successful in developing a reliable and valid situation-response SE contingency questionnaire, which measures adolescents' SE contingency in domains identified as important within multidimensional self-concept models and which allows to distinguish between upward and downward contingencies. Additionally, our questionnaire includes specific and tangible events which may impact adolescents' self-esteem. Results clearly illustrate the need to distinguish between these upward and downward contingencies. Specifically, our findings suggest that SE contingency is a double-edged sword for adolescents' well-being: Although upward contingencies may be beneficial, downward contingencies appear unmistakably detrimental. 


\section{References}

Bos, A. E. R., Huijding, J., Muris, P., Vogel, L. R. R. \& Biesheuvel, J. (2010). Global, contingent and implicit self-esteem and psychopathological symptoms in adolescents. Personality and Individual Differences, 48, 311-316. Doi: 10.1016/j.paid.2009.10.025

Burwell, R. A., \& Shirk, S. R. (2003). Development and validation of the self-worth contingency questionnaire $(S W C Q)$. Poster presented at the meeting for the Association for the Advancement of Behavior Therapy, Boston, November.

Burwell, R. A., \& Shirk, S. R. (2006). Self Processes in Adolescent Depression: The Role of Self-Worth Contingencies. Journal of Research on Adolescence, 16, 479-490. doi: 10.1111/j.1532-7795.2006.00503.x

Crocker, J., Luhtanen, R. K., Cooper, M. L., \& Bouvrette, A. (2003). Contingencies of selfworth in college students: Theory and measurement. Journal of Personality and Social Psychology, 85, 894-908. Doi:10.1037/0022-3514.85.5.894

Deci, E. L., \& Ryan, R. M. (1995). Human autonomy: The basis for true self-esteem. In M. Kernis (Ed.), Efficacy, agency, and self-esteem (pp. 31-49). New York: Plenum.

Dupras, G., \& Bouffard, T. (2011). Development of the Self-Esteem Conditions Scale for French-speaking adolescents. European Review of Applied Psychology, 61, 89-99.

Harter, S. (1988). Manual for the Self-Perception Profile for Adolescents. Denver, CO: University of Denver.

Harter, S. (1999). The construction of the self. New York: Guilford Press.

Harter, S. (2006). The Self. In W. Damon \& R. M. Lerner (Eds.), Handbook of Child Psychology (pp. 505 - 570). New Jersey: Wiley.

Heppner, W. L., \& Kernis, M. H. (2011). High self-esteem: Multiple forms and their outcomes. In S. J. Schwartz, K. Luyckx, \& V. L. Vignoles (Eds.), Handbook of identity theory and research (Vol. 1, pp. 329-356). New York: Springer. 
Hooge, J., Decaluwé, L., \& Goossens, L. (2000). Identiteit en psychisch welbevinden [Identity and well-being]. In J. Hooge, H. De Witte, \& L. Walgrave (Eds.), Jongeren in Vlaanderen: Gemeten en geteld. 12- tot 18-jarigen over hun leefwereld en toekomst (pp. 35-58). Leuven, Belgium: Universitaire Pers.

IBM. (2015). IBM SPSS Statistics for Windows, Version 23. Armonk, NY: IBM Corp.

Johnson, M., \& Blom, V. (2007). Development and validation of two measures of contingent self-esteem. Individual Differences Research, 5, 300-328.

Knee, C. R., Canevello, A., Bush, A. L., \& Cook, A. (2008). Relationship-contingent selfesteem and the ups and downs of romantic relationships. Journal of Personality and Social Psychology, 95, 608-627.

Lawrence, J. S., \& Crocker, J. (2009). Academic contingencies of self-worth impair positively- and negatively-stereotyped students' performance in performance-goal settings. Journal of Research in Personality, 43, 868-874.

Marsh, H.W. (1992). Self Description Questionnaire (SDQ) II: A theoretical and empirical basis for the measurement of multiple dimensions of adolescent self-concept. A test manual and research monograph. Macarthur, New South Wales, Australia: University of Western, Sydney, Faculty of Education.

Marsh, H. W., Ellis, L., Parada, L., Richards, G. \& Heubeck, B. G. (2005). A short version of the Self Description Questionnaire II: Operationalizing criteria for short-form evaluation with new applications of confirmatory factor analyses. Psychological Assessment, 17, 81102. DOI: $10.1037 / 1040-3590.17 .1 .81$

Marsh, H. W., \& Shavelson, R. (1985). Self-concept: Its multifaceted, hierarchical structure. Educational Psychologist, 20, 107-125.

Muthén, B. O., \& Muthén, L. K. (1998-2010). Mplus version 6.1 [statistical software]. Los Angeles, CA: Muthén \& Muthén. 
Paradise, A. W., \& Kernis, M. H. (1999). Development of the Contingent Self-esteem Scale. Unpublished data, University of Georgia.

Petersen, A. C., Compas, B. E., Brooks-Gunn, J., Stemmler, M., Ey, S., \& Grant, K. E. (1993). Depression in adolescence. American Psychologist, 48, 155-168.

Roberts, R. E.., \& Sobhan, M. (1992). Symptoms of depression in adolescence: A comparison of Anglo, African, and Hispanic American. Journal of Youth and Adolescence, 21, 639651.

Salmela-Aro, K., \& Tynkkynen, L. (2012). Gendered pathways in school burnout among adolescents. Journal of Adolescense, 35, 929-939. doi: org/10.1016/j.adolescence. 2012.01.001

Shavelson, R. J., Hubner, J. J., \& Stanton, G. C. (1976). Self-concept: Validation of construct interpretations. Review of Educational Research, 46, 407-441.

Simons, J., \& Vangenechten, L. (2002). Toepassing van de Self Description Questionnaire II voor het nagaan van self-esteem op Vlaamse Jongeren van 16 en 17 jaar. In J. Simons (Red.), Actuele themata uit de psychomotorische therapie, Jaarboek 2002 [Actual themes from psychomotor therapy, Year book 2002] (pp. 125-152). Leuven: Acco.

Soenens, B., Vansteenkiste, M., \& Luyten, P. (2010). Toward a domain-specific approach to the study of parental psychological control: Distinguishing between dependency-oriented and achievement-oriented psychological control. Journal of Personality, 78, 217-256. doi: 10.1111/j.1467-6494.2009.00614.x

Sowislo, J. F., Orth, U., \& Meier, L. L. (2014). What constitutes vulnerable self-esteem? Comparing the prospective effects of low, unstable, and contingent self-esteem on depressive symptoms. Journal of Abnormal Psychology, 123, 737-753. 
Treffers, D. A., Goedhart, A. W., Veerman, J. W., Van den Bergh, B. R. H., Ackaert, L., \& DeRycke, L. (2002). De competentiebelevingsschaal voor adolescenten (CBSA). Handleiding. Lisse: Swets \& Zeitlinger.

Vonk, J., \& Smit, H. (2012). Optimal self-esteem is contingent: Intrinsic versus extrinsic and upward versus downward contingencies. European Journal of Personality, 26, 182-193.

Williams, T., Schimel, J., Hayes, J., \& Martens, A. (2010). The moderating role of extrinsic contingency focus on reactions to threat. European Journal of Social Psychology, 40, 300-320.

Wouters, S., Doumen, S., Germeijs, V., Colpin, H., \& Verschueren, K. (2013). Contingencies of self-worth in early adolescence: The antecedent role of perceived parenting. Social Development, 22, 242-258.

Wouters, S., Duriez, B., Luyckx, K., Klimstra, T., Colpin, H., Soenens, B., Verschueren, K. (2013). Depressive symptoms in university freshmen: Longitudinal relations with contingent self-esteem and level of self-esteem. Journal of Research in Personality, 47, 356-363. 


\section{Footnotes}

${ }^{1}$ Results from the cross-validation sample suggested a linear dependency involving downward peer relations. However, because this was not a consistent finding across both samples and the fit of the model was good in both samples, we continued analyses with the 8factor model. 
Table 1

Overview Existing Domain-Specific Self-esteem Contingency Questionnaires

\begin{tabular}{|c|c|c|c|c|}
\hline Questionnaire & Authors & Target group & Dimensions & $\begin{array}{l}\text { Number } \\
\text { of items }\end{array}$ \\
\hline Contingencies of Self-Worth Scale (CSWS) & $\begin{array}{l}\text { Crocker, Luhtanen, Cooper, } \\
\text { and Bouvrette } \\
(2003)\end{array}$ & College students & $\begin{array}{l}\text { Family support, Competition, Approval } \\
\text { from generalized others, Competencies, } \\
\text { Appearance, God's love, Virtue }\end{array}$ & 35 \\
\hline Self-Worth Contingency Questionnaire (SWCQ) & $\begin{array}{l}\text { Burwell and Shirk } \\
\text { (2003) }\end{array}$ & Adolescents & $\begin{array}{l}\text { Social acceptance and approval, } \\
\text { academic performance, activity } \\
\text { performance, Physical appearance + } \\
\text { Total score }\end{array}$ & 32 \\
\hline $\begin{array}{l}\text { Competence based SE and Relation } \\
\text { based SE scales }\end{array}$ & Johnson and Blom (2007) & College students & $\begin{array}{l}\text { Competence based self-esteem, } \\
\text { Relation based self-esteem }\end{array}$ & 26 \\
\hline Relationship-Contingent Self-Esteem & $\begin{array}{l}\text { Knee, Canevello, Bush, and } \\
\text { Cook (2008) }\end{array}$ & College students & Total score & 11 \\
\hline Academic contingencies of self-worth & $\begin{array}{l}\text { Lawrence and Crocker } \\
(2009)\end{array}$ & College students & Total score & 6 \\
\hline Extrinsic Contingency Focus Scale (ECFS) & $\begin{array}{l}\text { Williams, Schimel, Hayes, } \\
\text { and Martens } \\
(2010)\end{array}$ & College students & Total score & 20 \\
\hline $\begin{array}{l}\text { Self-Esteem Conditions Scale for French-Speaking } \\
\text { Adolescents }\end{array}$ & $\begin{array}{l}\text { Dupras and Bouffard } \\
\text { (2011) }\end{array}$ & Adolescents & $\begin{array}{l}\text { Social acceptance, Physical } \\
\text { appearance, Sportive \& athletic } \\
\text { performance, Body weight, Academic } \\
\text { achievement + Total score }\end{array}$ & 30 \\
\hline Domain-specific Contingency of Self-esteem & Vonk and Smit (2012) & All ages ( $\geq 16$ years) & $\begin{array}{l}\text { Appearance, Social approval, } \\
\text { Performance, Intrinsic }\end{array}$ & 29 \\
\hline
\end{tabular}


Table 2

Overview of Corresponding Domains in Several Self-Esteem (Contingency) Questionnaires

SCQA SPPA

SDQ-II
Physical appearance $\quad$ Physical appearance

General school

(and math \& verbal)

Physical abilities

Sports competence

Athletic competence

Close friendship

)

Relationships

(same \& opposite sex)

Social acceptance

Social acceptance

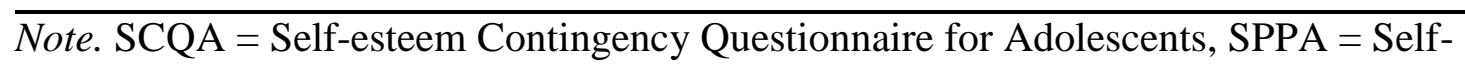

Perception Profile for Adolescents (Harter), SDQ = Self-Description Questionnaire - II (Marsh). 
Table 3

Model Fit Indices Based on CFAs

\begin{tabular}{lcccccc}
\hline & Scaled $\chi^{2}$ & df & CFI & RMSEA & $\begin{array}{c}90 \% \text { CI } \\
\text { RMSEA }\end{array}$ & SRMR \\
\hline 1-factor model & $3048.951^{*}$ & 594 & .659 & .083 & {$[.080-.086]$} & .083 \\
2-factor model & $2358.448^{*}$ & 593 & .755 & .070 & {$[.068-.073]$} & .070 \\
& & & & & & \\
6-factor model & $2129.041^{*}$ & 579 & .785 & .067 & {$[.064-.070]$} & .068 \\
& & & & & & \\
12-factor model & $1051.236^{*}$ & 528 & .927 & .041 & {$[.037-.044]$} & .040 \\
\hline
\end{tabular}

Note. $* p<.001$. 
Table 4

Standardized Factor Loadings and Fit Indices of the Final Model

Items

When l'm invited to a party, this has a positive effect on my self-esteem.

When I get lots of birthday wishes on my birthday, this has a positive effect on how I think about myself.

A priori label

Upward social

Final label

Upward social

When I have a close friend to do all sorts of stuff with, I feel more worthwhile.

If others stop talking when I join them, it has a negative effect on my self-esteem.

I view myself negatively if I'm chosen last when groups are created.

Upward friendship

Downward social

If my closest friend chooses somebody else to go out with, I feel bad about myself.

Downward social

I experience an increase in self-esteem when people compliment me about my appearance.

When my new hairstyle looks good, I feel more worthwhile.

Downward friendship

When someone says I'm good-looking, my self-esteem increases.

Upward appearance

Upward appearance

When I have zits, my self-esteem decreases.

Upward appearance

When someone gives a negative remark about my appearance, it has a negative effect on how I think about

myself.

Downward appearance

Downward appearance

I feel bad when my hair looks bad.

Downward appearance

When a teacher praises me about a good test result, I feel better about myself.

When I get good grades for a course, this has a positive effect on how I think about myself.

Upward academic

I feel more worthwhile when my grades on my report card are higher than I expected.

I think bad about myself when I make lots of mistakes in my schoolwork.

Upward academic

Upward academic

I think I am less worthy when I fail a course.

Downward academic

Downward academic

When I can't answer a question of the teacher, I feel less worthy.

When I can demonstrate an exercise during physical education, I feel more worthy.

When I get good grades in physical education, it has a positive effect on my self-esteem.

Downward academic

I feel worthwhile when I perform well in a sports game.

Upward sports

Upward sports

Upward sports

When I give a bad pass during a sports game, I feel worse about myself.

I think bad about myself when I miss an open chance during a sports game.

Downward sports

Downward sports

When I can't keep up during physical education, this has a negative effect on my self-

Downward sports

\begin{tabular}{|c|c|c|}
\hline Final label & $\lambda$ & $a$ \\
\hline & .67 & \\
\hline \multirow[t]{2}{*}{ Upward peer relations } & .64 & .67 \\
\hline & .61 & \\
\hline & .63 & \\
\hline \multirow[t]{3}{*}{ Downward peer relations } & .76 & .69 \\
\hline & .59 & \\
\hline & .77 & \\
\hline \multirow[t]{2}{*}{ Upward appearance } & .70 & .79 \\
\hline & .81 & \\
\hline & .65 & \\
\hline Downward appearance & .76 & .70 \\
\hline
\end{tabular}

esteem.

scaled $\chi^{2}(224)=503.251, p<.001, \mathrm{RMSEA}=.046,90 \% \mathrm{Cl}[.040-.051], \mathrm{CFI}=.937, \mathrm{SRMR}=.039$

Note. All factor loadings were significant at $p<.001$. 
Table 5

Descriptive Statistics and Correlations

\begin{tabular}{|c|c|c|c|c|c|c|c|c|c|c|c|}
\hline & 1 & 2 & 3 & 4 & 5 & 6 & 7 & 8 & 9 & 10 & 11 \\
\hline 1. Upward academic & -- & & & & & & & & & & \\
\hline 2. Downward academic & $.53^{* * *}$ & -- & & & & & & & & & \\
\hline 3. Upward appearance & $.55^{\star \star \star}$ & $.32^{\star \star \star}$ & -- & & & & & & & & \\
\hline 4. Downward appearance & $.36^{\star * *}$ & $.46^{\star * *}$ & $.55^{\star \star \star}$ & -- & & & & & & & \\
\hline 5. Upward sports & $.43^{\star * *}$ & $.34^{* \star \star}$ & $.34^{* * *}$ & $.20^{* \star *}$ & -- & & & & & & \\
\hline 6. Downward sports & $.30^{\star * *}$ & $.52^{\star \star \star}$ & $.23^{* * *}$ & $.41^{* \star *}$ & $.59^{\star \star \star}$ & -- & & & & & \\
\hline 7. Upward peer relations & $.59^{\star \star *}$ & $.42^{\star * \star}$ & $.66^{* \star *}$ & $.44^{* * *}$ & $.38^{* * *}$ & $.29^{\star \star \star}$ & -- & & & & \\
\hline 8. Downward peer relations & $.45^{\star \star *}$ & $.60^{* \star *}$ & $.45^{\star \star *}$ & $.62^{* * *}$ & $.38^{* \star *}$ & $.56^{\star * *}$ & $.48^{\star * *}$ & -- & & & \\
\hline 9. CSWS - Academic & $.66^{* * *}$ & $.53^{\star \star \star}$ & $.39^{* \star *}$ & $.37^{* * *}$ & $.29^{\star \star \star}$ & $.26^{* \star *}$ & $.45^{\star \star *}$ & $.41^{* \star \star}$ & -- & & \\
\hline 10. CSWS - Appearance & $.30^{* * *}$ & $.32^{* * *}$ & $.56^{* \star *}$ & $.62^{* * *}$ & $.12^{* \star}$ & $.23^{\star \star *}$ & $.41^{\star \star *}$ & $.42^{* \star *}$ & $.39^{\star \star \star}$ & -- & \\
\hline 11. CSWS - Social acceptance & $.29^{* * *}$ & $.42^{* \star *}$ & $.32^{* * *}$ & $.57^{* * *}$ & $.14^{* * *}$ & $.35^{\star * *}$ & $.36^{* * *}$ & $.55^{\star * \star}$ & $.39^{\star * *}$ & $.54^{* * *}$ & -- \\
\hline Academic self-concept & $.16^{* \star *}$ & .06 & $.15^{* \star *}$ & $.10^{*}$ & $.17^{\star \star \star}$ & $.08^{*}$ & $.15^{\star \star *}$ & $.11^{* *}$ & $.30^{\star \star \star}$ & $.09^{*}$ & .04 \\
\hline Appearance self-concept & $.12^{\star \star}$ & $-.10^{*}$ & $.23^{\star \star \star}$ & $-.12^{\star \star}$ & $.17^{\star \star \star}$ & -.05 & $.11^{*}$ & -.07 & .05 & .01 & $-.17^{\star \star *}$ \\
\hline Sports self-concept & .01 & -.05 & .03 & -.08 & $.49^{* * *}$ & $.24^{* * *}$ & .00 & -.02 & -.01 & $-.09^{*}$ & $-.10^{*}$ \\
\hline Close friendship self-concept & .05 & $-.10^{*}$ & $.10^{*}$ & -.02 & $.12^{* *}$ & -.02 & $.16^{* * *}$ & -.03 & .04 & .04 & -.06 \\
\hline Social self-concept & $-.10^{*}$ & $-.32^{\star * *}$ & -.05 & $-.26^{\star \star \star}$ & -.00 & $-.19^{* * *}$ & $-.13^{\star *}$ & $-.30^{\star * *}$ & $-.12^{* \star}$ & $-.13^{* *}$ & $-.23^{\star * *}$ \\
\hline Depressive symptoms & .07 & $.27^{\star \star \star}$ & .03 & $.25^{\star \star \star}$ & -.07 & $.13^{\star \star}$ & .04 & $.22^{\star \star \star}$ & .06 & $.17^{\star \star \star}$ & $.19^{\star \star \star}$ \\
\hline Dependency oriented PC & $.11^{* *}$ & $.27^{* \star *}$ & .07 & $.18^{* * *}$ & $.13^{\star * *}$ & $.23^{* * *}$ & $.12^{* *}$ & $.24^{* * *}$ & .07 & .06 & $.14^{* * *}$ \\
\hline Achievement oriented PC & $.14^{* * *}$ & $.28^{\star \star \star}$ & $.11^{* *}$ & $.21^{* \star *}$ & .06 & $.19^{\star \star \star}$ & $.14^{\star \star *}$ & $.23^{\star \star *}$ & $.10^{*}$ & $.09^{*}$ & $.13^{* *}$ \\
\hline$M$ & 4.51 & 3.30 & 4.51 & 3.70 & 3.75 & 3.41 & 4.48 & 3.88 & 4.75 & 4.64 & 4.28 \\
\hline$S D$ & 0.90 & 1.06 & 0.87 & 1.12 & 1.09 & 1.16 & 0.86 & 1.04 & 1.06 & 0.96 & 1.39 \\
\hline
\end{tabular}

Note. ${ }^{*} p<.05 . * * p<.01 . * * * p<.001$. 
Table 6

Multiple Regression Analyses of SE Contingencies on Psychological Control

\begin{tabular}{|c|c|c|c|c|c|c|c|c|}
\hline & \multicolumn{2}{|c|}{ Academic } & \multicolumn{2}{|c|}{ Appearance } & \multicolumn{2}{|c|}{ Sports } & \multicolumn{2}{|c|}{ Peer relations } \\
\hline & $B$ & $\beta$ & $B$ & $\beta$ & $B$ & $\beta$ & $B$ & $\beta$ \\
\hline \multicolumn{9}{|l|}{ Upward } \\
\hline Sex & .29 & $.16^{* * *}$ & .25 & $.15 * * *$ & -.08 & -.04 & .25 & $.15^{* * *}$ \\
\hline Track & .09 & $.08 *$ & .15 & $.13 * * *$ & .02 & .02 & .14 & $.12 * *$ \\
\hline Dependency oriented PC & .04 & .03 & -.02 & -.01 & .30 & $.18 * *$ & .08 & .06 \\
\hline Achievement oriented PC & .16 & $.15^{* *}$ & .14 & $.13^{*}$ & -.09 & -.07 & .12 & $.11^{*}$ \\
\hline$R^{2}$ & \multicolumn{2}{|c|}{.05} & \multicolumn{2}{|c|}{.05} & \multicolumn{2}{|c|}{.02} & \multicolumn{2}{|c|}{.06} \\
\hline \multicolumn{9}{|l|}{ Downward } \\
\hline Sex & .32 & $.15 * * *$ & .89 & $.40 * * *$ & .05 & .02 & .46 & $.22 * * *$ \\
\hline Track & .18 & $.13 * * *$ & .16 & $.11^{* *}$ & .23 & $.16^{* * *}$ & .25 & $.19 * * *$ \\
\hline Dependency oriented PC & .22 & $.13^{*}$ & .14 & .08 & .36 & $.20 * * *$ & .26 & $.16^{* *}$ \\
\hline Achievement oriented PC & .27 & $.21 * * *$ & .29 & $.21 * * *$ & .06 & .04 & .18 & $.14^{* *}$ \\
\hline$R^{2}$ & \multicolumn{2}{|c|}{.13} & \multicolumn{2}{|c|}{.22} & \multicolumn{2}{|c|}{.08} & \multicolumn{2}{|c|}{.15} \\
\hline
\end{tabular}

Note. Sex was coded 1 for girls and 0 for boys, Track was coded 1 for the vocational track, 2 for the technical/arts track, and 3 for the academic track. PC $=$ Psychological Control. ${ }^{*} p<.05 . * * p<.01 . * * * p<.001$. 
Table 7

Multiple Regression Analyses of Depressive Symptoms on SE Contingencies and SE Level

\begin{tabular}{|c|c|c|c|c|c|c|c|c|}
\hline & \multicolumn{2}{|c|}{ Academic } & \multicolumn{2}{|c|}{ Appearance } & \multicolumn{2}{|c|}{ Sports } & \multicolumn{2}{|c|}{ Peer relations } \\
\hline & $B$ & $\beta$ & $B$ & $\beta$ & $B$ & $\beta$ & $B$ & $\beta$ \\
\hline Sex & .09 & $.10 * *$ & -.02 & -.02 & .07 & $.08 *$ & .06 & .06 \\
\hline Track & -.07 & $-.12 * *$ & -.07 & $-.11 * *$ & -.08 & $-.13 * * *$ & -.08 & $-.13 * * *$ \\
\hline Upward contingency & -.03 & -.06 & -.02 & -.03 & -.05 & $-.11 *$ & -.04 & -.07 \\
\hline Downward contingency & .14 & $.33 * * *$ & .11 & $.26 * * *$ & .11 & $.27 * * *$ & .07 & $.15 * * *$ \\
\hline SE level & -.11 & $-.26 * * *$ & -.14 & $-.28 * * *$ & -.09 & $-.24 * * *$ & -.21 & $-.38 * * *$ \\
\hline$R^{2}$ & \multicolumn{2}{|c|}{.17} & \multicolumn{2}{|c|}{.16} & \multicolumn{2}{|r|}{.12} & \multicolumn{2}{|r|}{.20} \\
\hline
\end{tabular}

Note. Sex was coded 1 for girls and 0 for boys, Track was coded 1 for the vocational track, 2 for the technical/arts track, and 3 for the academic track. Results for peer relations were mentioned controlling for social self-concept, but controlling for friendship self-concept similar results were found: $\beta_{\text {upward contingency }}=$ $.02, n s ; \beta_{\text {downward contingency }}=.23, p<.001, \beta_{\text {SElevel }}=-.25, p<.001 . \mathrm{SE}=$ Self-Esteem. $* p<.05 . * * p<.01 . * * *<<.001$. 
Table 8

Multiple Regression Analyses with CSWS Subscales

\begin{tabular}{|c|c|c|c|c|c|c|}
\hline & \multicolumn{2}{|c|}{ Academic } & \multicolumn{2}{|c|}{ Appearance } & \multicolumn{2}{|c|}{ Social } \\
\hline & $B$ & $\beta$ & $B$ & $\beta$ & $B$ & $\beta$ \\
\hline \multicolumn{7}{|l|}{ SE contingency as $D V$} \\
\hline Sex & .46 & $.22 * * *$ & .54 & $.28 * * *$ & .75 & $.27 * * *$ \\
\hline Track & .22 & $.16^{* * *}$ & .20 & $.17 * * *$ & .56 & $.32 * * *$ \\
\hline Dependency oriented PC & -.02 & -.01 & -.00 & -.00 & .23 & $.11 *$ \\
\hline Achievement oriented PC & .18 & $.13^{*}$ & .14 & $.12 *$ & .14 & .08 \\
\hline$R^{2}$ & \multicolumn{2}{|c|}{.09} & \multicolumn{2}{|c|}{.12} & \multicolumn{2}{|c|}{.21} \\
\hline \multicolumn{7}{|l|}{ Depressive Symptoms as DV } \\
\hline Sex & .10 & $.11 * *$ & .02 & .02 & .04 & .04 \\
\hline Track & -.06 & $-.10 *$ & -.07 & $-.11 * *$ & -.09 & $-.16^{* * *}$ \\
\hline SE contingency & .06 & $.14 * * *$ & .09 & $.19 * * *$ & .05 & $.15 * * *$ \\
\hline SE level & -.13 & $-.29 * * *$ & -.16 & $-.32 * * *$ & -.21 & $-.38 * * *$ \\
\hline$R^{2}$ & \multicolumn{2}{|c|}{.10} & \multicolumn{2}{|c|}{.14} & \multicolumn{2}{|c|}{.20} \\
\hline
\end{tabular}

Note. Sex was coded 1 for girls and 0 for boys, Track was coded 1 for the vocational track, 2 for the technical/arts track, and 3 for the academic track. DV = Dependent Variable. ${ }^{*} p<.05 . * * p<.01 . * * * p<.001$. 